\title{
'n Ondersoek na Sekere Biolinguistiese Verskynsels by Hakkel
}

\author{
I. C. Uys, B.A. Log. (Rand), M.A. (Pretoria)
}

Hakkel is waarskynlik die kommunikasie-afwyking wat, op die gebied van die spraakpatologie, die meeste aan navorsing onderworpe was. Veral gedurende die jare 1930 tot 1940 is verskeie studies gedoen in verband met die kenmerke van hierdie probleem. Terapeute het meer bewus begin raak van die eienskappe en probleme van die hakkelaar en, afhangende van hulle persoonlike oriëntasie, is teorieë saamgestel wat as verwysingsraamwerk moes dien vir die verklaring van hakkelgedrag. In terme van hierdie verduidelikingsraamwerk dui die toestand vandag nog op 'n primitiewe stadium van ontwikkeling, met 'n massa teorieë en navorsingresultate wat weersprekende verslae lewer van 'n beperkte omvang van feite. Die aanneemlikste verklaring hiervoor is die gebrek aan volgehoue, versigtige, gekoördineerde en sistematiese navorsing, met die doel om 'n verklaring of beskrywing van die funksionele verhouding tussen alle beskikbare feite te gee. Ook wat hierdie navorsing betref, moet onthou word dat die geheel belangriker is as die som van die dele.

Sekere van die elemente wat alreeds ondersoek is, is die voorkoms van hakkel onder verskillende kulturele omstandighede. Die resultate van hierdie ondersoeke het egter gegewens aan die lig gebring wat nog steeds onverklaarbaar voorkom. Hoewel volgehoue studie 'n verband met die voorkoms, van hakkel in verskillende kulture an te beveel is, sal verklarings vir verskillende verskynsels alleenlik gevind kan word in 'n biolinguistiese benadering tot die aard van die hakkelgedrag onder hierdie verskillende omstandighede. 'n Biolinguistiese benadering word aanbeveel, omdat sulke studies 'n verband met die mens en sy gedrag, die lewende organisme bestudeer soos hy gemodifiseer word deur 'n bepaalde omgewing - in hierdie geval grootliks 'n linguistiese omgewing.

\section{Doel van die Studie}

Soos in die geval van vorige navorsing, is dit die doel van hierdie studie om die voorkoms van hakkel te ondersoek, in omgewings waar die taal die belangrikste kulturele onderskeid aantoon. Omdat 'n biolinguistiese benadering gevolg word, word egter gepoog om 'n stappie verder te gaan as om net die voorkoms van hakkel te bepaal. Dit is nodig om verklarings te gee om aan te toon waarom hierdie verskynsels openbaar word. Sulke verklarings kan gevind word in die verband tussen die voorkoms van hakkel en sekere linguistiesfonetiese verskynsels. Vorige studies, waarin Engelssprekende hakkelaars 
gebruik is, het reeds bewys dat hakkelaars meer op konsonante. as op vokale, hakkel. In die praktyk is egter gevind dat:

I. In Afrikaans die aanvangsvokaal (veral in die geval van 'n beklemtoonde lettergreep) met 'n glottale afsluiting net voor vibrasie, d.w.s. 'n harde aanset, begin word.

2. In Engels 'n sagte aanset, d.w.s. 'n geleidelike adduksie van die stemlippe tot by die punt van vibrasie, asook 'n geleidelike aanvang van vibrasie, by aanvangsvokale gebruik word.

3. Afrikaanssprekende hakkelaars wel geneig is om dikwels op vokale te hakkel, veral waar hulle in die inisiële posisie van 'n woord of morfeem voorkom.

Die hipotese, onderliggend aan hierdie eksperimentele studie, is dus dat die harde aanvang of aanset van vokale (d.w.s. glottale afsluiting), by Afrikaanssprekende hakkelaars tot 'n hoër frekwensie van hakkel lei, as wat die geval is by Engelssprekende hakkelaars, wat die sagte aanvang of aanset gebruik.

Die benadering tot 'n studie van hierdie aard is fisiologies en linguisties-foneties (dus biolinguisties), omdat die glottale afsluiting en die betekenis en belang daarvan, sowel as sekere kenmerke van foneem-realisering in verskillende tale aandag geniet. 'n Studie van die biolinguistiek beklemtoon die harmoniese werking van alle liggaamstelsels in spraak- en taaluiting. Lenneberg beklemtoon die feit dat taal, soos enige ander gedragspatroon, as 'n manifestasie van ingewikkelde fisiologiese prosesse beskou kan word. Die spraakprosesse is dus gemodifiseerde of gefragmenteerde biologiese funksies. Tydens spraakproduksie word die spiere teen so 'n vinnige tempo geaktiveer (of gedeaktiveer) dat dit alleenlik deur outomatismes, wat uit ingewikkelde tydspatrone bestaan, uitgevoer kan word. Temporale patroonvorming (in teenstelling met temporale wanorde) is dus klaarblyklik op 'n onderliggende fisiologiese ritme gegrond. Hierdie feite is veral interessant wanneer dit in die lig van die eienskappe van Afrikaans en Engels, as spreektale, beskou word. Engels is 'n aaneenvloeiende taal, waar sinsritme meer deur intensiteitsmodulasie aangedui word en waar koartikulasie 'n sterk invloed uitoefen.

Afrikaans daarenteen is meer segmenteel van aard, in die sin dat pouses (selfs tussen lettergrepe) met 'n harde aanset van die daaropvolgende vokaal, algemeen voorkom in die spraakpatroon. Hierdie afbakeningsfunksie van die glottale afsluiting beïnvloed dan ook die spraakritme tot 'n groot mate.

Terwyl hakkel as 'n fragmentasie van die spraakproses, of 'n spraakritmeversteuring, beskou word, kan die hipotese gestel word dat hierdie natuurlike neiging tot fragmentasie van spraakritme by sekere tale ook 'n merkbare invloed op die voorkoms van hakkel sal uitoefen.

\section{Voorafgaande Studie}

Hoewel verskeie taalkundiges al op die verskille in vokaalaanset by Afrikaans en Engels gedui het, is hierdie verskynsels nog nooit weten- 
skaplik bepaal nie. 'n Voorafgaande studie, om die metode van aanset by verskillende normaalsprekende taalgroepe te bepaal, is dus genoodsaak. Vir hierdie deel van dje studie is gebruik gemaak van die spraakmonsters wat verkry is van drie groepe proefpersone nl. Britse Engels, verkry van volwasse persone wat minder as 'n jaar in SuidAfrika woonagtig is, Suid-Afrikaanse Engels, verkry van Engelssprekende Suid-Afrikaners en Afrikaans, verkry van Afrikaanssprekende Suid-Afrikaners.

Die spektrografiese analise wat gemaak is van vokaalaanset, is uitsluitlik gebaseer op vokale aan die begin van 'n beklemtoonde lettergreep, hetsy aan die begin van 'n woord, of aan die begin van 'n tweede, beklemtoonde lettergreep. Klem is konstant gehou aangesien dit 'n faktor is, wat vokaalaanset kan beinvloed. Die spektrografiese analise het 'n baie duidelike graadverskil openbaar, sodat die vokaalaanset geklassifiseer kon word onder hard, medium en sag. Die resultate dui op 'n sterk verskuiwing van sagte na medium en harde aanset by die drie groepe, in die volgorde: Britse Engels, Suid-Afrikaanse Engels en Afrikaans. Die volgende groepneigings kom duidelik na vore. Britse Engels: 'n baie sterk neiging tot die sagte aanset $(75 \%)$ word gemerk, veral wanneer dit vergelyk word met die medium $(2 \%)$ en harde aanset $(4 \%)$.

Suid-Afrikaanse Engels: die gebruik van die sagte aanset $(67 \%)$ kom ook hier die sterkste na vore, hoewel die medium $(30 \%)$ en harde aanset $(3 \%)$ ook gebruik word.

Afrikaans: die voorkoms van medium (54\%) en harde aanset $(47 \%)$ is byna eweredig versprei by hierdie groep, terwyl die sagte aanset nie eenkeer voorgekom het nie.

Hoewel hierdie bevindings ooreenstem met vorige gegewens en verwagting, kan daar tog op twee interessante verskynsels gedui word, nl. die wedersydse invloed wat by Afrikaans en Suid-Afrikaanse Engels aangetref word en die feit dat die invloed van die inisiële klank op aanset sterker is as die invloed van klem.

\section{Eksperimentele Ontwerp en Prosedure}

Proefpersone: Volwasse hakkelaars, bo die ouderdom van 16 jaar, is as proefpersone gekies. Keuring, op grond van die erns van die hakkel, het geskied op grond van die volgende kriteria :

(a) Dat die persone hulleself as hakkelaars beskou;

(b) dat die eksperimenteerder simptome van onvlotheid, met gepaardgaande gedragsmanifestasies van sekondêre hakkel waargeneem het.

Op hierdie wyse is die resultate verkry van:

(i) 12 Engelssprekende, Suid-Afrikaanse manlike hakkelaars.

(ii) 11 Afrikaanssprekende Suid-Afrikaners, 9 mans en 2 dames.

\section{Toetsmateriaal}

Dieselfde toetsmateriaal is gebruik wat in die voorafgaande studie met die normale sprekers gebruik is, nl. 'n woordelys bestaande uit 140 
geselekteerde woorde. Alledaagse Engelse woorde is vir die Engelssprekende groep aangebied en bekende Afrikaanse woorde vir die Afrikaanssprekendes. Daar is vir verskeie redes besluit om-liewer van woordelyste as van spontane spraak of die lees van sinne, gebruik te maak.

(a) Daar bestaan nog geen genoegsame bewyse in verband met die voorkoms van wat beskou kan word as 'n aanvangsklank in die middel van 'n sin nie. Die moontlikheid van ko-artikulasie moet dus geëlimi. neer word.

(b) Verskeie veranderlikes, wat die eksperimentele resultate kan beïnvloed, moet konstant gehou word, bv. verwagting en posisie van die woord in die sin.

(c) Die aanbieding van woordelyste kan ook beheer uitoefen oor faktore soos woordlengte, grammatikale funksie, betekenisvolheid en verskeidenheid van aanvangsklanke.

(d) Terwyl twee taalgroepe betrek is kan die aanbieding van woordelyste sorg dra dat die spraakmonsters op fonetiese grondslag ooreenstem.

\section{Algemene Prosedure}

Elke proefpersoon is indiwidueel getoets. Die woorde is een vir een aangebied en geen tydsbeperking is gestel nie. Die beoordeling van die voorkoms van hakkelspasmas is gedoen deur twee opgeleide spraakterapeute, tydens die opname, asook volgens die bandopname. Hierdie prosedure is konstant gehou vir alle proefpersone.

\section{Resultate en Bespreking}

Die resultate is deur middel van twee statistiese prosedures verwerk. Vergelyking binne die groepe is verkry met die Wilcoxon Simmetrietoets, terwyl vergelyking tussen groepe vasgestel is met die normaalbenadering vir die verskil tussen twee verhoudings. Hierdie toetse het veral geskik geblyk te wees, omdat die studie van 'n relatief klein getal proefpersone gebruik gemaak het.

Om tot 'n slotsom te kom i.v.m. die hipotese, is die volgende verhoudings statisties bepaal :

1. Die verhouding in die voorkoms van hakkel tussen aanvangsvokale en aanvangskonsonante by elke persoon.

2. Die verhouding tussen die twee groepe met betrekking tot die voorkoms van hakkel op aanvangsvokale en aanvangskonsonante.

3. Die verhouding in die voorkoms van hakkel tussen vokale en konsonante aan die begin van die tweede, beklemtoonde lettergreep, by elke persoon.

4. Die verhouding tussen die twee groepe met betrekking tot die voorkoms van hakkel op vokale en konsonante aan die begin van die tweede, beklemtoonde lettergreep. 
Dit dien vermeld te word dat twee van die Afrikaanse hakkelaars vroulik is. Vorige navorsing het aangetoon dat laringeale spasmas dikwels by vrouens voorkom, soos ook hier opgemerk kan word uit die resultate van een vroulike proefpersoon. Die resultate vir beide vroulike proefpersone is egter behou in die ontleding, eerstens omdat bevind is dat die uitsprake nie verander het wanneer die persone weggelaat word nie, en tweedens om die aantal proefpersone in die groepe naastenby gelyk te hou.

\section{Die verhouding in die voorkoms van hakkel tussen aanvangsvokale en aanvangskonsonante by elke persoon.}

Tabel I: Die Voorkoms van Hakkel op Aanvangsvokale en Aanvangskonsonante BY ENGELSSPREKENDE HAKKELAARS

\begin{tabular}{cccc}
\hline Proefpersone & Aanvangsvokaal & Aanvangskonsonant & Totaal \\
\hline $1 . \mathrm{M}$ & 35 & 24 & 59 \\
$2 . \mathrm{M}$ & 4 & 19 & 23 \\
$3 . \mathrm{M}$ & 13 & 14 & 27 \\
$4 . \mathrm{M}$ & 18 & 4 & 22 \\
$5 . \mathrm{M}$ & 11 & 36 & 47 \\
$6 . \mathrm{M}$ & 18 & 40 & 58 \\
$7 . \mathrm{M}$ & 33 & 55 & 88 \\
8.M & 30 & 39 & 69 \\
$9 . \mathrm{M}$ & 3 & 17 & 20 \\
$10 . \mathrm{M}$ & 25 & 42 & 67 \\
$11 . \mathrm{M}$ & 2 & 10 & 12 \\
$12 . \mathrm{M}$ & 11 & 7 & 510 \\
\hline
\end{tabular}

Uit hierdie tabel kan afgelei word dat die nulhipotese van geen verskil tussen die voorkoms van hakkel op aanvangsvokale en aanvangskonsonante op die 5\%-peil van betekenis verwerp word. Hieruit blyk dit dus dat die voorkoms van hakkel op aanvangsvokale betekenisvol minder is as die voorkoms van hakkel op aanvangskonsonante.

Tabel II : Die Voorkoms van HaKkel op Aanvangsvokale en AanvangSKonsonante BY AFRIKAANSSPREKENDE HAKKELAARS

\begin{tabular}{cccc}
\hline Proefpersone & Aanvangsvokale & Aanvangskonsonante & Totaal \\
\hline $1 . \mathrm{M}$ & 10 & 6 & 16 \\
$2 . \mathrm{M}$ & 2 & 13 & 15 \\
$3 . \mathrm{M}$ & 20 & 39 & 59 \\
4.M & 5 & 16 & 21 \\
5.M & 4 & 9 & 13 \\
6.M & 53 & 25 & 78 \\
8.M & 17 & 13 & 30 \\
$9 . \mathrm{M}$ & 34 & 2 & 36 \\
$10 \mathrm{~V}$ & 4 & 2 & 66 \\
$11 . \mathrm{V}$ & 60 & 9 & 41 \\
\hline & 32 & 140 & -381 \\
\hline
\end{tabular}

Tydskrif van die Suid-Afrikaanse Logopediese Vereniging, Vol. 17, Nr. 1: Des. 1970 
In hierdie geval word die nulhipotese nie op die $5 \%$-peil van betekenis verwerp nie. Die afleiding is dus dat daar geen betekenisvolle verskil bestaan tussen die voorkoms van hakkel op aanvangsvokale en aanvangskonsonante nie.

\section{Die verhouding tussen die twee groepe met betrekking tot die voor- koms van hakkel op aanvangsvokale en aanvangskonsonante.}

In die volgende tabel word 'n uiteensetting gegee van die voorkoms van hakkel op aanvangsvokale, om sodoende groepneigings met mekaar te vergelyk.

TABEl III: Die VoOrkoms Van HaKkel op AanvangsVOKALE BY BEIDE GROEPE

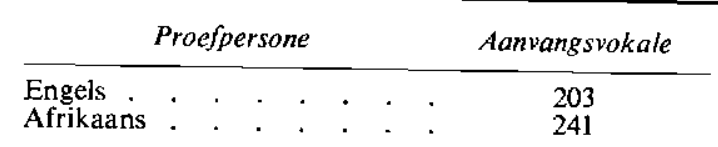

Die persentasie hakkel op aanvangsvokale by Engelssprekende hakkelaars is dus $24.2 \%$, terwyl dit by Afrikaanssprekende hakkelaars $31.3 \%$ is.

\section{Bespreking}

Die verkreë waardes dui aan dat daar op die $5 \%$-peil van betekenis wel 'n. verskil bestaan tussen die twee groepe. Die Afrikaanssprekende hakkelaars het dus betekenisvol meer op aanvangsvokale gehakkel as die Engelssprekende hakkelaars.

Wanneer hierdie resultate vergelyk word met 'n soortgelyke studie wat deur Hahn in Amerika uitgevoer is, word gevind dat dieselfde neiging, wat in die voorafgaande studie met normale sprekers gevind is, homself hier herhaal. Die Amerikaanse hakkelaars (wat van 'n sagter aanset gebruik maak as die Engelssprekende Suid-Afrikaanse

TABEL IV: DIE VOORKOMS VAN HAKKEL OP AANVANGSKONSONANIE BY BEIDE GROEPE'

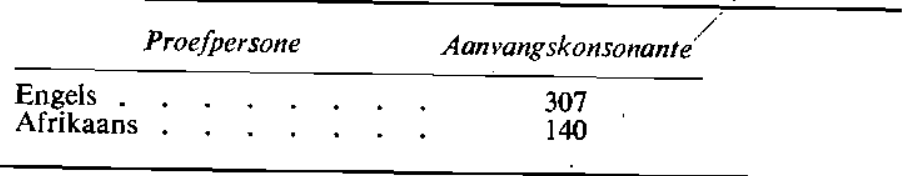

hakkelaars) het slegs op $2.9 \%$ van die aanvangsvokale gehakkel. Weereens neem die Engelssprekende Suid-Afrikaners die middelgroep in, terwyl die Afrikaanssprekende hàkkelaars die meeste op aanvangsvokale gehakkel het.

Journal of the South African Logopedic Society. Vol. 17, No. I: December 1970 
Die persentasie hakkel op aanvangskonsonante by die Engelssprekende hakkelaars is dus $36.5 \%$ terwyl dit by die Afrikaanssprekende hakkelaars $18.2 \%$ is.

\section{Bespreking}

Soos in die geval van aanvangsvokale, is ook hier 'n betekenisvolle verskil gevind tussen die twee groepe. Op die 5\%-peil van betekenis, het die Afrikaanssprekende hakkelaars minder op aanvangskonsonante gehakkel as die Engelssprekende hakkelaars.

Op grond van hierdie betekenisvolle bevindings kan dus afgelei word dat die twee taalgroepe van mekaar verskil met betrekking tot die voorkoms van hakkel op aanvangsvokale en aanvangskonsonante. 'n Ander motivering vir hierdie stelling word gevind in die vergelyking binne die groepe-dat die Engelssprekendes betekenisvol minder op aanvangsvokale gehakkel het as op aanvangskonsonante, terwyl die Afrikaanssprekendes geen betekenisvolle verskil toon nie.

3. Die verhouding in die voorkoms van hakkel tussen konsonante en vokale aan die begin van die tweede, beklemtoonde lettergreep, by elke persoon.

Sekere verskynsels in verband met foneemrealisering en hakkel dien as motivering vir 'n analise van die voorkoms van hakkel op die tweede, beklemtoonde lettergreep. Indien Ladefoged se siening korrek is, behoort die begin van die tweede lettergreep (veral omdat dit beklemtoon is) weereens 'n aanvangsklank te hê, wat vergelykbaar is met die aanvangsklank by die eerste lettergreep. Die feit dat klem tot 'n verhoogde voorkoms van hakkel lei kan ook hier in ag geneem word. Indien hierdie verskynsels 'n sterk invloed sou uitoefen op die voorkoms van hakkel, kan verwag word dat dieselfde patroon, as wat gevind is in die geval van aanvangsklanke, homself hier sal herhaal.

Tabel V: Die Voorkoms van Hakkel op Vokale en Konsonante aan die Begin Van diE TWeede, Beklemtoonde LetTergreep by Engelssprekende HakkelaArs

\begin{tabular}{cccc}
\hline Proefpersone & $\begin{array}{c}\text { Aanvangsvokaal } \\
\text { van 2e lettergreep }\end{array}$ & $\begin{array}{c}\text { Aanvangskonsonant } \\
\text { van 2elettergreep }\end{array}$ & Totaal \\
\hline 1.M & 17 & 5 & 22 \\
$2 . \mathrm{M}$ & 3 & 0 & 3 \\
$3 . \mathrm{M}$ & 2 & 0 & 2 \\
$4 . \mathrm{M}$ & 0 & 0 & 0 \\
$5 . \mathrm{M}$ & 4 & 4 & 8 \\
$6 . \mathrm{M}$ & 4 & 10 & 14 \\
$7 . \mathrm{M}$ & 12 & 3 & 15 \\
$8 . \mathrm{M}$ & 0 & 1 & 1 \\
$9 . \mathrm{M}$ & 1 & 2 & 3 \\
$10 . \mathrm{M}$ & 12 & 16 & 7 \\
$1 . \mathrm{M}$ & 5 & 2 & 2 \\
$12 . \mathrm{M}$ & 1 & 1 & 105 \\
\hline
\end{tabular}


Die nulhipotese kan hier nie op dic $5 \%$-peil van betekenis verwerp word nie, met ander woorde, geen verskil word gevind tussen die voorkoms van hakkel op vokale en konsonante aan die begin van dic tweede, beklemtoonde lettergreep by hierdie groep nie.

Tabel. VI: Die Voorkoms van Hakkel op. Vokale en Konsonante aAn die Begin VAN DIE TWEede, BEKLEMTOONDE LeTtergReEP By AFRIKaANSSPREKENDE HaKkELAars

\begin{tabular}{cccc}
\hline Proefpersone & $\begin{array}{c}\text { Aanvangsvokaal } \\
\text { van 2e lettergreep }\end{array}$ & $\begin{array}{c}\text { Aanvangskonsonant } \\
\text { van 2e lettergreep }\end{array}$ & Totaal \\
\hline 1.M & 3 & 4 & 7 \\
2.M & 1 & 2 & 3 \\
3.M & 3 & 15 & 18 \\
S.M & 0 & 2 & 2 \\
6.M & 4 & 1 & 5 \\
$7 . \mathrm{M}$ & 3 & 4 & 7 \\
8.M & 1 & 3 & 4 \\
9.M & 12 & 4 & 1 \\
l0.V & 1 & 0 & 16 \\
I1.V & 15 & 1 & 19 \\
\hline
\end{tabular}

Net soos in die geval van Tabel II is wecreens twee berekenings gedoen (met en sonder die vrouens) en beide berekenings dui daarop dat die nulhipotese nie op dic $5 \%$-peil van betekenis verwerp kan word nie. Daar bestaan dus geen betekenisvolle verskil tussen die voorkoms van hakkel op konsonante en vokale aan die begin van die tweede, beklemtoonde lettergreep nic.

Tabel VIl: Die VoOkKoms Van HaKkel op Vokale AaN DIE BEgIN VAN DIE TWEede, BEKLEMTOONDE LETTERGREEP BY BEIDE GROEPE

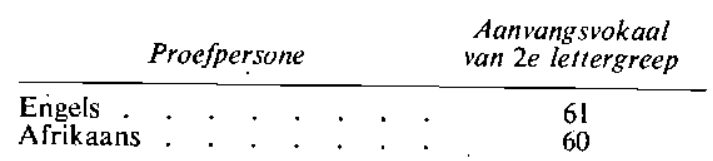

In vergelyking met die resultate van Tabel II kan hier gesien word dat dieselfde patroon herhaal word, $n \mathrm{l}$., dat daar in beide gevalle geen bctekenisvolle verskille bestaan nie.

4. Die verhouding tussen die twee groepe met betrekking tot die voorkoms van hakkel op vokale en konsonante aan die begin van die tweede, beklemtoonde lettergreep.

Tcrwyl die voorafgaande bespreking aangetoon het dat die patroon, wat gevind is in die geval van aanvangsklanke homself alleenlik in die geval van die Afrikaanssprekende hakkelaars herhaal, is die twee grocpe weer met mekaar vergelyk in 'n poging om die groepneigings vas te stel.

Journal of the South African Logopedic Society, Vol. 17, No. 1: December 1970 
Tabel VI is 'n aanduiding van die voorkoms van hakkel op vokale aan die begin van die tweede, beklemtoonde lettergreep en stem ooreen met die analise van aanvangsvokale in Tabel III.

Die persentasie hakkel op vokale aan die begin van die tweede, beklemtoonde lettergreep is dus: Engels: $25.4 \%$ en Afrikaans: $27.3 \%$.

\section{Bespreking}

Volgens analise met die normaalbenadering word gevind dat daar op die 5\%-peil van betekenis geen verskil tussen die twee groepe bestaan nie.

Wat betref die aanvangsvokale is daar wel 'n verskil tussen die twee groepe gevind en wel dat die Afrikaanssprekende hakkelaars betekenisvol meer op aanvangsvokale gehakkel het.

Omdat die spraakmonsters in bogenoemde twee gevalle nie gelykwaardig is nie, is dit nie moontlik om 'n definitiewe vergelyking te tref nie. Daar kan egter sekere verskynsels aan die hand gedoen word wat aanleiding kan gee tot hierdie verskille.

Die sterk neiging onder Engelssprekendes om te streef na 'n vloeiende spraakmelodie, wat veral deur vokale oorgedra word, kan aanleiding gee tot die verskynsel van ko-artikulasie, met ander woorde, dat dit moeilik is om te bepaal wanneer daar binne die woord nog 'n aanvangsklank voorkom. Die invloed van die inisiële klank blyk dus nog sterker - te wees as die invloed van klem op die voorkoms van hakkel.

Die herhaling van dieselfde patroon in beide gevalle van die Afrikaanssprekende hakkelaars is verklaarbaar op grond van die feit dat Afrikaans, soos Noord-Duits 'n afgebroke ,springerige" kwaliteit openbaar. Kort pouses kom dikwels tussen lettergrepe voor (in teenstelling met Engels) en dit kan dui op 'n nuwe aanvang voor 'n tweede, beklemtoonde lettergreep. Die invloed van die inisiële klank op die voorkoms van hakkel, kan dus in beide gevalle geld.

'n Vergelyking tussen die twee groepe mel betrekking tot die voorkoms van hakkel op konsonante aan die begin van die tweede, beklemtoonde lettergreep word in Tabel VIII gestel. Dit is weereens vergelykbaar met die voorkoms van hakkel op aanvangskonsonante soos aangedui in Tabel IV.

Tabel V1lI: Die Voorkoms vav Hakkel op KonSONANTE aAN DIE BEgIN VAN DIE TWEEDE, BEKLEMTOONDE LetTergreep by Beide Groepe

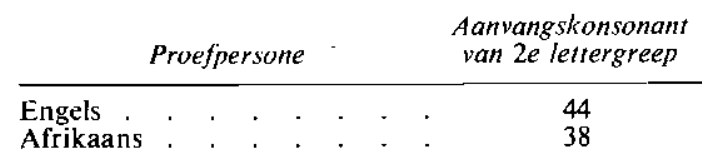

Die persentasie hakkel op konsonante aan die begin van die tweede, beklemtoonde lettergreep is dus: Engels: $18.3 \%$ en Afrikaans $17.3 \%$. 
Weereens is daar op die $5 \%$-peil van betekenis geen verskil tussen die twee groepe gevind nie.

Die Engelssprekende hakkelaars het egter betekenisvol meer gehakkel op aanvangskonsonante as die Afrikaanssprekende groep. Dieselfde verklaring wat voorgehou is in die geval van die voorkoms van hakkel op vokale kan moontlik hier van toepassing wees.

Uit bogenoemde bespreking kan die afleiding dus gemaak word dat, in die geval van die Engelssprekende hakkelaars, die aanvangsklank van die tweede, beklemtoonde lettergreep nie nog 'n aanvangsklank in die ware sin van die woord is nie: Die vloeiendheid van die taal, koartikulasie en sinsritme oefen klaarblyklik 'n sterk invloed uit.

In Afrikaans oefen die neiging tot fragmentasie 'n sterk invloed uit en het die harde aanset 'n sterk afbakeningsfunksie. Dit is dus verstaanbaar dat dieselfde patroon hier gevolg word by die aanvang van die tweede, beklemtoonde lettergreep.

Die hipotese wat gestel is, dat hakkel meer by Afrikaanssprekendes sal voorkom op aanvangsvokale, is dus bewys. Op grond van die ondersoeke wat uitgevoer is met die 3 groepe normale sprekers, blyk dit ook asof die harde aanset wat by Afrikaans voorkom, die oorsaak van hierdie verskynsel is.

\section{Gevolgtrekkings}

Die primêre doel van hierdie studie was om. die invloed van sekere biolinguistiese verskynsels op hakkel te ondersoek. Die navorsing is dus ook veral gerig op laringeale funksie onder twee verskillende omstandighede :

1. Laringeale funksie in foneem-realisering by twee tale: Afrikaans en Engels.

2. Laringeale funksie as gevolg van foneem-realisering, by hakkel.

Die resultate bevestig grotendeels die hipotese: 'n sterk verskuiwing van sagte na medium en harde aanset van vokale is waargeneem by die drie groepe normale sprekers, in die volgorde: Britse Engels, SuidAfrikaanse Engels en Afrikaans. Dit beaam weereens die stelling dat Engels, as spreektaal meer aaneenvloeiend is, waar spraakritme eerder deur intensiteitsmodulasie as deur onderbreking gehandhaaf word. Afrikaans daarenteen, toon hoofsarklik die harde vokadaanset, wat veral voorkom op aanvangsklanke. Aangesien hieŕdie verskynsel homself herhaal het in die geval.van die tweede, beklemtoonde lettergreep, word hier bevestiging gevind vir die bewering dat Afrikaans, as spreektaal, meer segmenteel van aard is, deurdat die afbakeningsfunksie van die glottale afsluiting deur 'n kort pouse voorafgegaan is. Die resultate het verder aan die lig gebring dat Suid-Afrikaanse Engels eienskappe van beide Britse Engels en Afrikaans toon.

Die resultate van die hakkelaars kan dus nou in die lig van die voorkoms van hierdie linguistiese verskynsels verklaar word: Afrikaans- 
sprekende hakkelaars het betekenisvol meer op aanvangsvokale gehakkel as Engelssprekende hakkelaars. Die gevolgtrekking kan dus gemaak word dat die glottale afsluiting, wat 'n algemene verskynsel in die Afrikaanse spreektaal is, lei tot 'n laringeale hakkelspasma. Die relatief sagter aanvang wat deur Suid-Afrikaanse Engelse gebruik word, het betekenisvol minder hakkelspasmas ontlok, terwyl Amerikaanse studies bewys dat hakkel selde op aanvangsvokale voorkom.

Aangesien hierdie selfde patroon homself uitsluitlik in die geval van die Afrikaanssprekende hakkelaars op die tweede, beklemtoonde lettergreep herhaal het, bevestig dit die vermoede dat aanvangsvokale in Afrikaans ook in die middel van 'n woord kan voorkom.

Uit hierdie studie blyk dit dus dat 'n biolinguistiese benadering tot 'n verklaring van die voorkoms van hakkel positiewe resultate oplewer. Daar is egter nog sekere vrae wat deur verdere navorsing beantwoord moet word :

1. Wat is 'n aanvangsklank en wanneer kom dit voor by normale sprekers uit verskillende taalgroepe?

2. Sou die resultate dieselfde gewees het indien sinne gelees is of spraakmonsters van spontane spraak verkry is?

3. Wat is die frekwensie van laringeale spasmas tydens die voorkoms van hakkel?

Uit hierdie vrae blyk dit dat daar nog 'n hele nuwe veld braak lê. Dit kan wees dat daar in die beantwoording van hierdie vrae ' $n$ oplossing vir die raaisel van hakkel gevind kan word.

\section{Opsomming}

Verskeie navorsingsprojekte het al gepoog om die voorkoms van hakkel in verskillende kulture vas te stel, sonder om 'n verklaring van die voorkoms en aard van hakkelgedrag deur middel van 'n biolinguistiese benadering aan te bied.

Linguisties-fonetiese faktore, soos vokale aanvangsmetodes, dui op 'n verskil tussen Afrikaans en Engels. Die harde aanset van aanvangsvokale in Afrikaans blyk 'n oorsaak te wees van 'n verhoogde voorkoms van hakkel op aanvangsvokale. 'n Biologiese proses (laringeale spanning, glottale afsluiting en verhoogde subglottale lugdruk) aan die een kant en 'n linguistiese verskynsel (die spesifieke eienskappe van foneem-realisering in verskillende tale) aan die ander kant, veroorsaak klaarblyklik die patologiese reaksie (laringeale hakkel).

\section{Summary}

Various research projects have aimed to explain the occurrence of stuttering amongst various cultural groups, without offering an explanation of the occurrence and nature of the stuttering behaviour in terms of a biolinguistic approach.

Linguistic phonetic factors, such as vocal initiation, indicate a difference between English and Afrikaans. The hard attack on the initial 
vowels in Afrikaans appear to result in an increased frequency of stuttering on these initial vowels. A biological process (laryngeal tension, glottal closure and increased sub-glottal pressure) on the one hand, and a linguistic phenomenon (the specific properties of the phonemic system in different languages) on the other hand, appear to be the cause of the pathological reaction (laryngeal stuttering).

\section{Bibliografie}

1. Brown, S. F.: A further study of stuttering in relation to various speech sounds. Q.J.S., Vol. 24, 1938, p. 390-897.

2. Brown, S. F.: Stuttering with relation to word accent and word position. Journal of Abnormal and Social Psychology. Vol. 33, 1938, p. 112-130. 3. Brown, S. F.: The loci of stuttering in the spech sequence. J.S.D. Vol. 10 ,
1945, p. 181-192.

4. Hahn, F. F.: $A$ study of the relationship between stuttering occurrence and phonetic factors in oral reading. J.S.D. Vol. 7, 1942, p. 143-151.

5. Judson, L. S. and Weaver, A. T.: Voice Science. Appleton-Century-Crofts Inc., New York, 1965.

6. Ladefoged, P.: Three Areas of Experimental Phonetics. Oxford University Press, London, 1967.

7. Le Roux, T. H. and Picnaar, P. de V.: Afrikaanse Fonetiek. Juta \& Kie Bpk., Kaapstad en Johannesburg, 1927.

8. Lenneberg, E. H.: Biological Foundarions of Language. John Wiley \& Sons, New York, London, Sydney, 1967.

9. Luchsinger, R. and Arnold, G. E.: Voice-Speech-Language, Clinical Communicology: Its Physiology and Pathology. Wadsworth Publ. Co. Inc.,
Belmont, California, 1965.

10. McDonald, E. T.: Articulation: Testing and Treatment: A sensory-motor Approach. Stanwix House Inc., Pittsburgh, 1968.

11. Meader, C. L. and Muyskens, J. H.: A Handbook of Biolinguistics, Part 1. Herbert C. Weller, Toledo Spcech Clinic, Inc., Ohio, 1962. 